\title{
Introgressive origin of the radiate groundsel, Senecio vulgaris L. var. hibernicus Syme: Aat-3 evidence
}

\author{
RICHARD J. ABBOTT, PAUL A. ASHTON \& DAVID G. FORBES \\ Department of Biology and Preclinical Medicine, Sir Harold Mitchell Building, University of St Andrews, St Andrews, \\ Fife KY16 9TH, Scotland, U.K.
}

\begin{abstract}
A survey of allelic variation at the Aat-3 locus in Senecio squalidus and $S$. vulgaris revealed that the Aat $-3 c$ allele, which was present at high frequency in British populations of $S$. squalidus, was also common in British radiate groundsel ( $S$. vulgaris var. hibernicus) but was rare among individuals of the non-radiate groundsel ( $S$. vulgaris var. vulgaris) which co-occurred with var. hibernicus and was absent from British, Irish and mainland European populations monomorphic for var. vulgaris. This evidence is taken as confirmation of an introgressive origin of $S$. vulgaris var. hibernicus across a chromosome barrier following hybridization between $S$. vulgaris var. vulgaris $(2 n=40)$ and radiate S. squalidus $(2 n=20)$ and backcrossing to $S$. vulgaris var. vulgaris. Genetic analysis showed that the Aat-3 locus, which is duplicated in $S$. vulgaris is not linked to the ray floret locus controlling capitulum type. It is suggested that the close association between the Aat-3c allele and the radiate allele in populations of $S$. vulgaris polymorphic for capitulum type may be maintained by selection favouring a co-adapted complex of genes introgressed from $S$. squalidus, although alternative explanations are not ruled out. The introgression of the Aat-3c allele and associated genetic material from $S$. squalidus into $S$. vulgaris is likely to have enhanced the level of genetic variation present within $S$. vulgaris and may have been a factor that has favoured the spread of $S$. vulgaris var. hibernicus in Britain following its origin last century.
\end{abstract}

Keywords: introgression, isozyme variation, population genetic structure, Senecio vulgaris, Senecio squalidus.

\section{Introduction}

Gene exchange between species via introgressive hybridization is a well known phenomenon among plants (Anderson, 1949; Stebbins, 1959, 1969; Grant, 1981; Briggs \& Walters, 1984). Several studies have utilized allozymes to demonstrate the presence of backcrossed individuals in hybrid swarms of wild plants (Levin, 1975; Ellstrand et al., 1985; Olivieri, 1985; Rollo et al., 1985; Soltis \& Soltis, 1986; Arnold et al., 1990); however, there is little evidence that such individuals evolve into new taxa distributed beyond the zone of active hybridization (Heiser, 1973). One example of such an event in the genus Helianthus (Heiser, 1951), namely the origin of Helianthus annuus ssp. texanus Heiser, following introgression of genes from $H$. debilis ssp. cucumerifolium (Torrey and Gray) Heiser into $H$. annuus $\mathrm{L}$., is supported by recent evidence from a study of Rieseberg et al. (1990) which used DNA markers. However, another example in the same genus, i.e. the origin of a Californian weedy race of $H$. bolanderi following introgression of genes from $H$. annuus into a serpentine race of $H$. bolanderi (Heiser, 1949), is disputed by the allozyme and molecular evidence (Rieseberg et al., 1988). Other possible examples of the evolution of stabilized introgressants in wild plants (Grant, 1950; Levin, 1963; Ornduff, 1967; Bloom, 1976; Davis, 1985) have yet to be subjected to similar detailed analysis involving genetic markers.

Within the British flora a good example of the origin of a new taxon via introgression is considered to be that of the inland radiate morph of the groundsel, Senecio vulgaris L. var. hibernicus Syme, $2 n=40$ (Stace, 1987). This morph was first described in the British Isles in 1866 (Syme, 1875) from material which grew around Cork in Ireland; however, Crisp (1972) has since identified a specimen of the same variant collected from 
Oxford in 1832 and deposited in the herbarium at Liverpool University. The variant is believed to have originated following introgression of genes from the introduced radiate species Senecio squalidus $\mathrm{L}$. $(2 n=20)$ into the common and widespread nonradiate morph of groundsel, Senecio vulgaris L. var. vulgaris L. $(2 n=40)$. Initial evidence in support of this origin (reviewed by Stace, 1977) was based on: (i) the parallel spread of $S$. squalidus and $S$. vulgaris var. hibernicus in Britain over the past 150 years (Crisp, 1972), following the escape of $S$. squalidus from the Oxford Botanic Garden at the end of the 18th Century (Druce, 1927); and (ii) the presence of morphological characters in var. hibernicus, which are intermediate to those exhibited by $S$. squalidus and $S$. vulgaris var. vulgaris, e.g. leaf characters (Monaghan \& Hull, 1976).

More compelling evidence for an introgressive origin of var. hibernicus was advanced by Ingram et al. (1980) who successfully synthesized several fertile radiate plants that were tetraploid $(2 n=40)$, and resembled var. hibernicus, by backcrossing the artificially synthesized triploid hybrid $S$. vulgaris var. vulgaris $\times S$. squalidus $(2 n=30)$, to the female parent (var. vulgaris), and then selfing the products. The extreme low fertility of the triploid hybrid and the reduced fertility of the initial backcross products, led Ingram et al. (1980) to accept Stace's view that the origin of radiate var. hibernicus was a rare event and that factors other than frequent introgression must account for the rapid spread of this taxon in Britain in recent years.

Despite the historical, morphological and crossing evidence that favours an introgressive origin of var. hibernicus, it remains feasible that the variant originated following a single gene mutation in non-radiate var. vulgaris. Capitulum type in $S$. vulgaris (radiate v. non-radiate) is controlled by a single gene with two alleles showing incomplete dominance (Trow, 1912). As non-radiate mutants naturally occur at low frequency in some British populations of the related radiate $S$. squalidus L. (Ingram \& Taylor, 1982) and $S$. jacobea L. (Harper \& Wood, 1957), it is feasible that the reverse mutation might occur in Senecio as in certain other Compositae e.g. Bidens cernua L. (Stace, 1977).

The introgressive origin of var. hibernicus would be more certain if it were shown that along with the radiate allele, other genes specific to $S$. squalidus had been introduced into $S$. vulgaris and were now present at high frequency in var. hibernicus, but absent from non-radiate $S$. vulgaris material isolated from $S$. squalidus.

Here we report on a study of allozyme variation for aspartate aminotransferase (AAT) in $S$. vulgaris and $S$. squalidus, which provides evidence that genetic material in addition to the radiate allele has been introgressed from $S$. squalidus into $S$. vulgaris. Based on this and the previous evidence reviewed by Stace (1987), we propose that the radiate variant of $S$. vulgaris (var. hibernicus) is a classic example of a taxon which originated in recent times as a stabilized introgressant, and has since become widely distributed in Britain.

\section{Materials and methods}

Seeds (achenes) or whole plants of the radiate (var. hibernicus) and non-radiate (var. vulgaris) variants of $S$. vulgaris were collected from 13 British populations that were polymorphic for capitulum type. Similarly, seeds or plants were collected from 15 populations that were monomorphic for non-radiate var. vulgaris (seven British populations, one Irish and seven from mainland Europe), and also from 20 British populations of $S$. squalidus. The locations of populations and the size of samples collected are listed in Tables 3 and 4. The distribution of British populations sampled of $S$. vulgaris and $S$. squalidus is illustrated in Fig. 1. Populations of var. vulgaris from mainland Europe were isolated from the natural distribution of $S$. squalidus in Europe (Alexander, 1979). Nearly all other populations of $S$. vulgaris grew in areas where $S$. squalidus also occurred or was present nearby. In most instances, plants were sampled from populations which grew on open wasteground or along the edges of paths and pavements in urban areas; however, some samples of var. vulgaris came from more natural open habitats, e.g. sand dunes (at Aberffraw) and cliff tops (on Puffin Island). The seed of each parent plant sampled was germinated to provide one offspring per mother plant for electrophoresis. Alternatively, material from individuals collected directly from the field was used for electrophoresis. On average, material from approximately 30 individuals per taxon was analysed electrophoretically per population.

Plants raised from seed, or transplanted from the field, were cultivated in a greenhouse in pots or trays containing a peat-based compost. Starch gel electrophoresis was conducted on crude protein extracts of leaf tissue. The extraction buffer was composed of 50 $\mathrm{ml}$ of gel buffer (see below); $37 \mathrm{mg} \mathrm{KCl} ; 14 \mathrm{mg} \mathrm{MgCl}$; $18 \mathrm{mg}$ EDTA (tetrasodium); $2 \mathrm{ml}$ mercaptoethanol; 0.5 $\mathrm{ml}$ Triton X-100; and $25 \mathrm{mg}$ PVPP. Homogenates were applied to paper wicks, and enzymes were separated in 11 per cent $(\mathrm{w} / \mathrm{v})$ starch gels run at a constant voltage of $250 \mathrm{~V}$. The electrode buffer was $0.192 \mathrm{M}$ boric acid adjusted to $\mathrm{pH} 8.3$ with lithium hydroxide (giving a final $\mathrm{LiOH}$ molarity of $0.03 \mathrm{M}$ ), while the gel buffer was composed of one part electrode buffer to nine parts of 


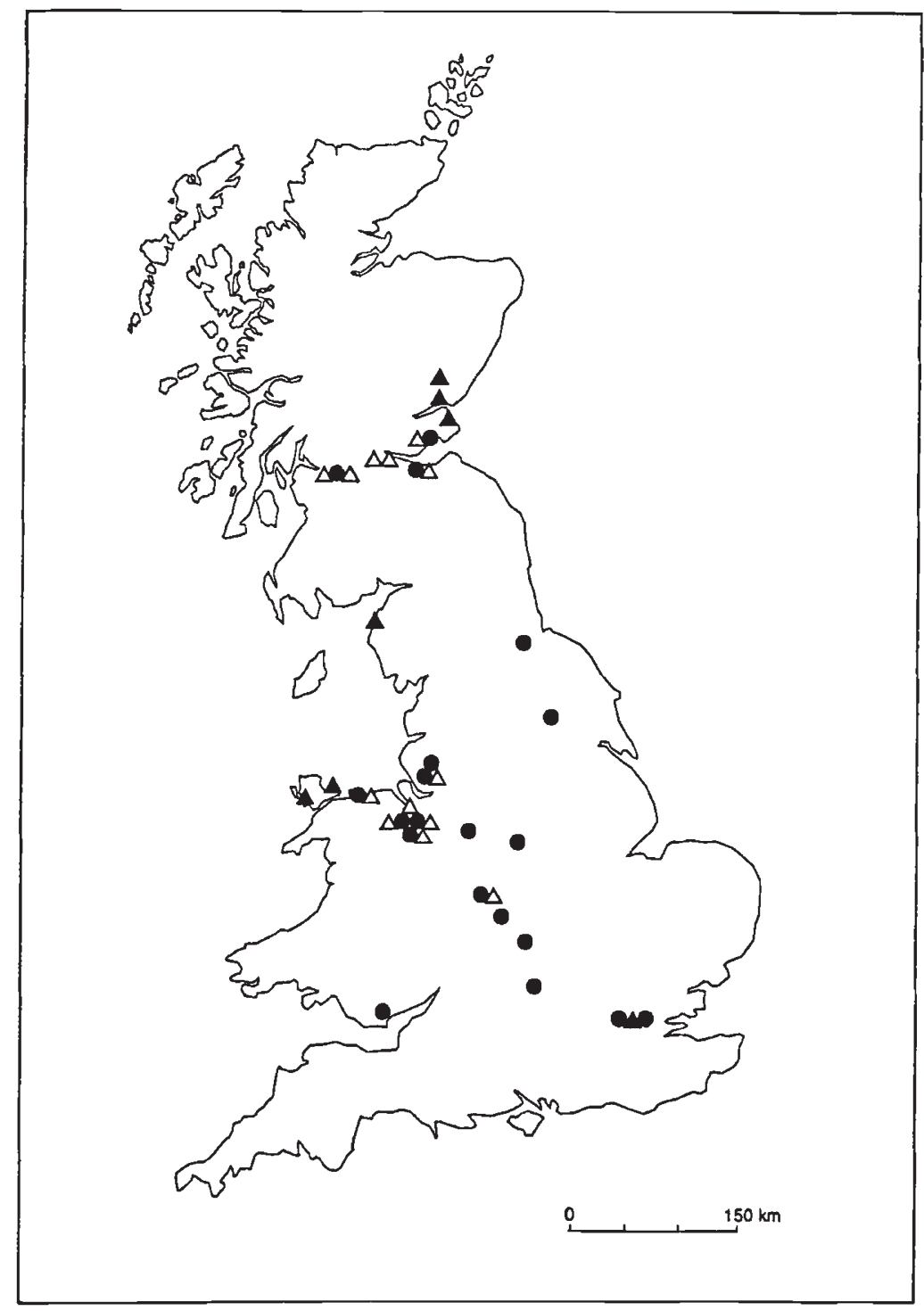

Fig. 1 Distribution of British populations of Senecio spp. surveyed for Aat -3 variation: S. squalidus $(\bullet)$; $S$. vulgaris var. vulgaris and var. hibernicus $(\Delta) ; S$. vulgaris var. vulgaris (৯).

$0.05 \mathrm{~m}$ Tris $0.007 \mathrm{M}$ citrate, $\mathrm{pH}$ 8.3. Gels were stained for AAT at $37^{\circ} \mathrm{C}$. The stain solution was composed of $50 \mathrm{ml} 0.1 \mathrm{~m}$ Tris- $\mathrm{HCl}(\mathrm{pH} 8.5), 18 \mathrm{mg} \alpha$-ketoglutaric acid, $65 \mathrm{mg}$ aspartic acid, $250 \mathrm{mg}$ PVP, $25 \mathrm{mg}$ EDTA (tetrasodium), $710 \mathrm{mg} \mathrm{Na} \mathrm{HPO}_{4}, 1 \mathrm{mg}$ pyridoxal-5phosphate, and $200 \mathrm{mg}$ Fast Blue BB (after Gottlieb, 1973).

\section{Genetic analysis of AAT variants}

Three zones of activity were detected on gels stained for AAT in both $S$. squalidus and $S$. vulgaris (Ashton, 1990). Two zones, designated as Aat-1 and Aat-2 were located close to each other, approximately equidistant from the origin and the anodal front. Within each of these zones a band was either present or absent depending on the individual surveyed. Individuals were frequently double-banded producing both Aat-1 and
Aat-2 isozymes, or single-banded for one or other isozymes. No individuals were found which lacked both bands. A genetic analysis (Ashton, 1990) failed to establish a simple model of inheritance for the presence/absence of Aat-1 and Aat-2 isozymes in $S$. squalidus and these isozymes were not investigated in the present study. In the third zone of activity, nearer to the origin (Fig.2), S. squalidus individuals exhibited either a single fast allozyme $(A a t-3 b)$, a single slow allozyme $(A a t-3 C)$, or were triple-banded possessing both allozymes and an additional intermediate allozyme. A genetic analysis (Ashton, 1990), confirmed that the Aat-3 allozymes in $S$. squalidus are the products of a single diallelic gene with the triple-banded phenotype representing the heterozygote.

In $S$. vulgaris, individuals are typically triple banded within the Aat-3 zone of activity (Ashton, 1990), although a rare six-banded phenotype also occurs (Fig. 


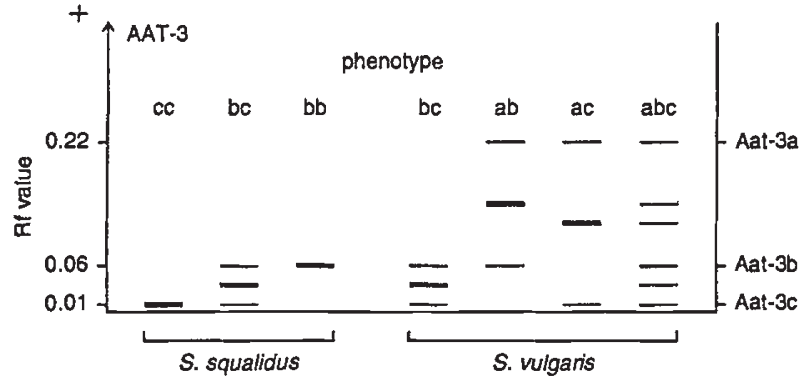

Fig. 2 Electrophoretic phenotypes resolved for Aat 3 in Senecio squalidus and $S$. vulgaris. Staining intensity of bands varied in the six-banded $A a t-3$ phenotype observed in $S$. vulgaris reflecting gene dosage.
2). Three different triple-banded phenotypes have been resolved in $S$. vulgaris and are designated as Aat3ab, Aat-3ac and Aat-3bc (Fig. 2). To establish the genetic basis of this variation, and also the possibility of linkage between alleles encoding Aat-3 allozymes and those at the ray floret locus controlling capitulum type in $S$. vulgaris, a genetic analysis was conducted which involved examination of selfed offspring, and $F_{1}$ and $F_{2}$ families produced from reciprocal crosses between available radiate and non-radiate inbred lines that differed in Aat-3 phenotype (Tables 1 and 2). Crosses were made after emasculating capitula of maternal plants using the procedure described by Ornduff

Table $1 \chi^{2}$ test for segregation ratio of genotypes for capitulum and $A a t-3$ type in the $\mathrm{F}_{2} \mathrm{~s}$ of reciprocal crosses between radiate (RR) and non-radiate (NN) $S$. vulgaris lines. Designated Aat-3 genotypes of parents are enclosed in brackets

\begin{tabular}{|c|c|c|c|c|c|c|c|c|c|c|}
\hline \multirow{2}{*}{$\begin{array}{l}\text { Parents } \\
\text { Capitulum type }\end{array}$} & \multicolumn{9}{|c|}{$\mathrm{F}_{2}$ genotype } & \multirow[t]{2}{*}{$\chi_{(2)}^{2} \dagger$} \\
\hline & $R R$ & $R N$ & $N N$ & & & & & & & \\
\hline L26-RR, $(\mathrm{cc}, \mathrm{bb}) \times \mathrm{M} 2-\mathrm{NN},(\mathrm{aa}, \mathrm{bb})$ & 43 & 100 & 92 & & & & & & & $25.65^{* * *}$ \\
\hline $\mathrm{M} 2-\mathrm{NN},(\mathrm{aa}, \mathrm{bb}) \times \mathrm{L} 26-\mathrm{RR},(\mathrm{cc}, \mathrm{bb})$ & 43 & 103 & 50 & & & & & & & 1.01 \\
\hline $\mathrm{L} 15-\mathrm{RR},(\mathrm{aa}, \mathrm{bb}) \times \mathrm{S} 2-\mathrm{NN},(\mathrm{cc}, \mathrm{bb})$ & 73 & 117 & 58 & & & & & & & 2.60 \\
\hline $\mathrm{S} 2-\mathrm{NN},(\mathrm{cc}, \mathrm{bb}) \times \mathrm{L} 15-\mathrm{RR},(\mathrm{aa}, \mathrm{bb})$ & 72 & 113 & 55 & & & & & & & 3.22 \\
\hline $\mathrm{M} 12-\mathrm{RR},(\mathrm{cc}, \mathrm{aa}) \times \mathrm{M} 28-\mathrm{NN},(\mathrm{aa}, \mathrm{bb})$ & 45 & 90 & 50 & & & & & & & 0.40 \\
\hline $\mathrm{M} 28-\mathrm{NN},(\mathrm{aa}, \mathrm{bb}) \times \mathrm{M} 12-\mathrm{RR},(\mathrm{cc}, \mathrm{aa})$ & 60 & 92 & 48 & & & & & & & 2.72 \\
\hline M22-RR, $($ cc,aa $) \times M 29-N N,(a a, b b)$ & 41 & 65 & 43 & & & & & & & 2.48 \\
\hline $\mathrm{M} 29-\mathrm{NN},(\mathrm{aa}, \mathrm{bb}) \times \mathrm{M} 22-\mathrm{RR},(\mathrm{cc}, \mathrm{aa})$ & 12 & 24 & 21 & & & & & & & 4.26 \\
\hline L13-RR, $(c c, a a) \times M 24-N N,(a a, b b)$ & 27 & 73 & 35 & & & & & & & 1.84 \\
\hline Aat -3 type & $a a, b b$ & $a c, b b$ & $c c, b b$ & & & & & & & \\
\hline $\mathrm{L} 26-\mathrm{RR},(\mathrm{cc}, \mathrm{bb}) \times \mathrm{M} 2-\mathrm{NN},(\mathrm{aa}, \mathrm{bb})$ & 60 & 127 & 56 & & & & & & & 0.63 \\
\hline $\mathrm{M} 2-\mathrm{NN},(\mathrm{aa}, \mathrm{bb}) \times \mathrm{L} 26-\mathrm{RR},(\mathrm{cc}, \mathrm{bb})$ & 47 & 111 & 47 & & & & & & & 1.41 \\
\hline $\mathrm{L} 15-\mathrm{RR},(\mathrm{aa}, \mathrm{bb}) \times \mathrm{S} 2-\mathrm{NN},(\mathrm{cc}, \mathrm{bb})$ & 62 & 132 & 58 & & & & & & & 0.70 \\
\hline \multirow[t]{2}{*}{$\mathrm{S} 2-\mathrm{NN},(\mathrm{cc}, \mathrm{bb}) \times \mathrm{L} 15-\mathrm{RR},(\mathrm{aa}, \mathrm{bb})$} & 57 & 135 & 56 & & & & & & & 1.96 \\
\hline & $c c, a a$ & $c c, a b$ & $c c, b b$ & & & & & & & \\
\hline F6-RR, $(c c, a a) \times B 7-N N,(c c, b b)$ & 42 & 95 & 31 & & & & & & & 4.32 \\
\hline \multirow[t]{2}{*}{$\mathrm{B} 7-\mathrm{NN},(\mathrm{cc}, \mathrm{bb}) \times \mathrm{F} 6-\mathrm{RR},(\mathrm{cc}, \mathrm{aa})$} & 72 & 167 & 57 & & & & & & & $6.40^{*}$ \\
\hline & $c c, a a$ & $c c, a b$ & $a a, a b$ & $a a, c c$ & $a a, a c$ & $b b, c c$ & $a a, b c$ & $a c, b b$ & $a b, c c$ & $\chi_{\{8\}}^{2} \ddagger$ \\
\hline M12-RR, $($ cc,aa $) \times$ M28-NN,(aa,bb) & 13 & 19 & 18 & 14 & 32 & 21 & 11 & 17 & 12 & 11.92 \\
\hline
\end{tabular}

$\dagger$ Test of $1: 2: 1$ ratio.

$¥$ Test of $1: 2: 1: 2: 4: 2: 1: 2: 1$ ratio (i.e. due to disomic digenic inheritance).

Derivation of material: B (Brymbo), F (Ffrith), L (Leith), M (Methil), S (Southsea).

NB: average percentage of seed sown per $F_{2}$ family producing individuals scored was 74.7 per cent for capitulum type and 76.4 per cent for Aat-3 type. 
Table 2 Results of $\chi^{2}$ contingency tests for joint segregation of alleles at ray floret locus and first Aat-3 locus; and ray floret locus and second Aat-3 locus in $S$. vulgaris. Designated Aat -3 genotypes of parents are enclosed in brackets

\begin{tabular}{|c|c|}
\hline Parents & $\chi_{(4)}^{2}$ \\
\hline \multicolumn{2}{|l|}{ First Aat-3 locus } \\
\hline L26-RR, $(c c, b b) \times M 2-N N,(a a, b b)$ & 7.62 \\
\hline $\mathrm{M} 2-\mathrm{NN},(\mathrm{aa}, \mathrm{bb}) \times \mathrm{L} 26-\mathrm{RR},(\mathrm{cc}, \mathrm{bb})$ & 1.02 \\
\hline $\mathrm{L} 15-\mathrm{RR},(\mathrm{aa}, \mathrm{bb}) \times \mathrm{S} 2-\mathrm{NN},(\mathrm{cc}, \mathrm{bb})$ & 1.66 \\
\hline $\mathrm{S} 2-\mathrm{NN},(\mathrm{cc}, \mathrm{bb}) \times \mathrm{L} 15-\mathrm{RR},(\mathrm{aa}, \mathrm{bb})$ & 3.08 \\
\hline M12-RR, $(c c, a a) \times M 28-N N,(a a, b b)$ & 0.58 \\
\hline $\mathrm{M} 28-\mathrm{NN},(\mathrm{aa}, \mathrm{bb}) \times \mathrm{M} 12-\mathrm{RR},(\mathrm{cc}, \mathrm{aa})$ & 5.97 \\
\hline M22-RR, $(c c, a a) \times M 29-R R,(a a, b b)$ & 0.85 \\
\hline M29-RR, $(a a, b b) \times M 22-N N,(c c, a a)$ & 2.86 \\
\hline L13-RR, $(c c, a a) \times M 24-N N,(a a, b b)$ & 0.98 \\
\hline M24-NN, $(a a, b b) \times$ L13-RR, $(c c, a a)$ & 0.77 \\
\hline $\mathrm{F} 5-\mathrm{RR},(\mathrm{cc}, \mathrm{aa}) \times \mathrm{S} 7-\mathrm{NN},(\mathrm{aa}, \mathrm{bb})$ & 5.50 \\
\hline $\mathrm{S} 7-\mathrm{NN},(\mathrm{aa}, \mathrm{bb}) \times \mathrm{F} 5-\mathrm{RR},(\mathrm{cc}, \mathrm{aa})$ & 4.37 \\
\hline \multicolumn{2}{|l|}{ Second $A$ at -3 locus } \\
\hline F6-RR, $(c c, a a) \times B 7-N N,(c c, b b)$ & 0.08 \\
\hline $\mathrm{B} 7-\mathrm{NN},(\mathrm{cc}, \mathrm{bb}) \times \mathrm{F} 6-\mathrm{RR},(\mathrm{cc}, \mathrm{aa})$ & 4.40 \\
\hline M12-RR, $(c c, a a) \times M 28-N N,(a a, b b)$ & $14.03^{* *}$ \\
\hline $\mathrm{M} 28-\mathrm{NN},(\mathrm{aa}, \mathrm{bb}) \times \mathrm{M} 12-\mathrm{RR},(\mathrm{cc}, \mathrm{aa})$ & 1.80 \\
\hline M22-RR,(cc,aa) $\times$ M29-NN,(aa,bb) & 6.97 \\
\hline M29-NN, $(a a, b b) \times M 22-R R,(c c, a a)$ & 2.79 \\
\hline L13-RR, $(c c, a a) \times M 24-N N,(a a, b b)$ & 3.00 \\
\hline M24-NN,(aa,bb) × L13-RR,(cc,aa) & 3.19 \\
\hline $\mathrm{F} 5-\mathrm{RR},(\mathrm{cc}, \mathrm{aa}) \times \mathrm{S} 7-\mathrm{NN},(\mathrm{aa}, \mathrm{bb})$ & 6.71 \\
\hline S7-NN, $(\mathrm{aa}, \mathrm{bb}) \times \mathrm{F} 5-\mathrm{RR},(\mathrm{cc}, \mathrm{aa})$ & 2.91 \\
\hline
\end{tabular}

NB: $\chi_{(4)}^{2}=9.49$ when $P=0.05$.

(1964). Selfed and crossed capitula were enclosed in bags made of lens tissue before and following treatment until seed was set.

\section{Results}

\section{Genetic analysis of Aat-3 variation in S. vulgaris}

Selfed offspring of $S$. vulgaris lines bred true for capitulum type and Aat-3 phenotype. Failure of each triplebanded phenotype to segregrate on selfing confirmed that the Aat-3 locus is duplicated in $S$. vulgaris with each locus homozygous for different alleles. The $F_{1}$ offspring of all crosses bore capitula with short ray florets and exhibited a six-banded $A a t-3 a b c$ phenotype in which the staining intensity of bands reflected gene dosage and therefore Aat-3 genotype. A six-banded $\mathrm{F}_{1}$ phenotype is expected for a tetraploid individual which is heterozygous for three alleles encoding a dimeric enzyme, due to the production of three intragenic heterodimers and three homodimeric allozymes.
In regard to capitulum type (Table 1 ), a significantly distorted ratio from the expected 1:2:1 ratio was observed in two out of $14 \mathrm{~F}_{2}$ families examined; however, in each case the ratio produced by the reciprocal cross was not significantly different from expected. The occurrence of distorted ratios is frequently observed in material of hybrid origin (Weeden \& Wendel, 1989) and this may account for the distortions recorded in the present analysis. That said, no irregularities in the normal pattern of disomic monogenic inheritance have been recorded in previous genetic analyses of capitulum type in S. vulgaris (Trow, 1912; Hull, 1974; R. J. Abbott, unpublished observations).

All four crosses for Aat-3, between the Aat-3ab and Aat-3bc phenotypes, produced $\mathrm{F}_{2}$ families in which the segregation ratio was not significantly different from $1: 2: 1$ (Table 1). This ratio would be expected following crosses between parental genotypes designated as $A a t$ $3 a a, b b$ and $A a t-3 c c, b b$ respectively. The cross between the $A a t-3 a c$ and $A a t-3 b c$ phenotypes also segregated $1: 2: 1$ in one family, while in the $F_{2}$ of the reciprocal the expected three phenotypes were produced despite a distorted segregation ratio. A 1:2:1 segregation ratio in the $\mathrm{F}_{2}$ of this cross would occur with parental genotypes designated as $A a t-3 c c, a a$ and $A a t-3 c c, b b$ respectively. Finally, seven of the eight crosses between the $A a t-3 a c$ and $A a t-3 a b$ phenotypes segregated nine genotypes in the $F_{2}$ in a $1: 2: 1: 2: 4: 2: 1: 2: 1$ ratio as expected with parental genotypes designated as Aat$3 c c, a a$ and $A a t-3 a a, b b$ respectively (assuming independent segregation of the two Aat-3 loci). In the remain ing $F_{2}$ family, the ratio was significantly distorted although all nine genotypes were recovered. Taken overall, the results confirm that there are two unlinked $A a t-3$ loci present in S. vulgaris, and that the Aat-3a allele occurs at each locus.

With two unlinked Aat-3 loci present in S. vulgaris, measurement of linkage to the ray floret locus requires consideration of each Aat-3 locus in turn. Crosses between radiate plants of $A a t-3 c c, b b$ genotype and non-radiate plants of $A a t-3 a a, b b$ genotype measure linkage between the ray floret locus and the first Aat-3 locus, while crosses between radiate individuals of Aat$3 c c, a a$ genotype and non-radiate plants of $A a t-3 c c, b b$ genotype estimate linkage between the ray floret locus and the second Aat-3 locus. $\mathrm{F}_{2}$ data from crosses between radiate plants of $A a t-3 c c, a a$ genotype and non-radiate plants of $A a t-3 a a, b b$ genotype provide estimates of linkage between the ray floret locus and each Aat-3 locus taken in turn. Chi-squared contingency tests of the joint segregation of capitulum type and Aat-3 type revealed no evidence of linkage between the ray floret locus and either Aat-3 locus in all except one cross examined (Table 2). In the single 
cross which showed significant joint segregation of capitulum type and Aat-3 type at the second Aat-3 locus analysed, a recombination fraction and its standard error were calculated using the maximum likelihood procedures of Allard (1956). This was performed by means of the LINKAGE-1 program of Suiter et al., (1983). The recombination fraction between the pair of loci remained high, $r=0.44 \pm 0.04$. Given the absence of significant joint segregation of the two loci in the reciprocal cross, and the results for the other crosses examined, it is concluded that the ray floret locus is not linked to either Aat-3 locus found in $S$. vulgaris.

\section{Genetic diversity}

S. squalidus. In all populations of $S$. squalidus, the Aat$3 c$ allele was more common that the alternative $A a t-3 b$ allele (Table 3), and over all individuals surveyed its frequency was estimated to be 74 per cent. Measures of gene diversity (Nei, 1973) at the Aat-3 locus showed that within-population diversity $(H s=0.3643)$ accounted for most of the total gene diversity $(H t=0.3916)$, between-population diversity being low $(D s t=0.0273)$. This pattern of diversity is expected in species that reproduce by predominant outcrossing (Hamrick \& Godt, 1990). F-statistics (Wright, 1951), computed using the method of Hartl (1981), revealed that the total inbreeding coefficient ( Fit $=0.2723$ ) was greater than expected with panmixia, due largely to a deficiency of heterozygotes from expected (Fis $=0.2174)$, rather than genetic subdivision between populations $(F s t=0.0701)$. However, only in three of the 20 populations surveyed were the observed genotype frequencies significantly different from those

Table 3 Allele frequencies, observed heterozygosity $\left(H_{0}\right)$ and Wright's Fixation Index $\left(F_{0}\right)$ at the Aat -3 locus in populations of S. squalidus

\begin{tabular}{|c|c|c|c|c|c|c|}
\hline \multirow[b]{2}{*}{ Population } & \multirow{2}{*}{$\begin{array}{l}\text { National Grid } \\
\text { Reference }\end{array}$} & \multirow{2}{*}{$\begin{array}{l}\text { Sample } \\
\text { size }\end{array}$} & \multicolumn{2}{|c|}{$\begin{array}{l}\text { Allele } \\
\text { frequency }\end{array}$} & \multirow[b]{2}{*}{$H_{0}$} & \multirow[b]{2}{*}{$F_{0}$} \\
\hline & & & $b$ & $c$ & & \\
\hline \multicolumn{7}{|l|}{ England } \\
\hline Banbury & SP463404 & 50 & 0.34 & 0.66 & 0.360 & +0.198 \\
\hline Birmingham & SP092876 & 21 & 0.31 & 0.69 & 0.333 & +0.220 \\
\hline Darlington & NZ296146 & 15 & 0.33 & 0.67 & $0.000^{*}$ & +1.000 \\
\hline Dartford & TQ555743 & 25 & 0.32 & 0.68 & 0.400 & +0.081 \\
\hline Derby & SK362356 & 44 & 0.30 & 0.70 & 0.455 & -0.094 \\
\hline Kingston-u-Thames & TQ191691 & 48 & 0.16 & 0.84 & 0.312 & -0.185 \\
\hline Oxford & SP505065 & 46 & 0.33 & 0.67 & 0.434 & +0.011 \\
\hline St Helens & SJ524926 & 46 & 0.22 & 0.78 & 0.304 & +0.108 \\
\hline Stoke-on-Trent & SJ886407 & 49 & 0.09 & 0.91 & 0.184 & -0.102 \\
\hline Warwick & SP286655 & 44 & 0.48 & 0.52 & 0.500 & -0.010 \\
\hline Wigan & SD594034 & 36 & 0.18 & 0.82 & 0.250 & +0.155 \\
\hline York & SE612518 & 26 & 0.40 & 0.60 & 0.500 & -0.037 \\
\hline \multicolumn{7}{|l|}{ Scotland } \\
\hline Glasgow & NS534671 & 34 & 0.19 & 0.81 & 0.206 & +0.334 \\
\hline Edinburgh & NT268765 & 44 & 0.15 & 0.85 & 0.252 & +0.008 \\
\hline Methil & NT376995 & 26 & 0.35 & 0.65 & 0.453 & -0.020 \\
\hline \multicolumn{7}{|l|}{ Wales } \\
\hline Cardiff & ST173733 & 22 & 0.32 & 0.68 & $0.000^{*}$ & +1.000 \\
\hline Mochdre & SH813774 & 26 & 0.42 & 0.58 & 0.308 & +0.370 \\
\hline \multicolumn{7}{|l|}{ Wrexham } \\
\hline Brymbo & SJ296539 & 33 & 0.15 & 0.85 & 0.182 & +0.293 \\
\hline Rhostyllen & SJ312492 & 27 & 0.31 & 0.69 & $0.259^{*}$ & +0.399 \\
\hline Southsea & SJ306515 & 25 & 0.00 & 1.00 & 0.000 & +1.000 \\
\hline Total & & 687 & 0.26 & 0.74 & 0.303 & +0.213 \\
\hline
\end{tabular}

Allele frequencies have been rounded up to two decimal places.

*Observed genotypic frequencies significantly different from expectation under

Hardy-Weinberg equilibrium $(P<0.05)$. 
expected at Hardy-Weinberg equilibrium. If the Fis value of 0.2174 was due entirely to selfing $(s)$, then an average selfing rate of approximately 36 per cent would be postulated for S.squalidus in the wild

$$
\left(s=1-\frac{1-F}{1+F}\right) \text {. }
$$

This value is unexpectedly high given the very low automatic selfing ability previously reported for $S$. squalidus (Gibbs et al., 1975). Spatial substructuring of populations or assortative mating are alternative factors which might lead to a deficiency of heterozygotes in $S$. squalidus populations; these factors, together with the direct estimation of outcrossing rates in the wild, will require investigation in future.

$S$. vulgaris. Because the Aat-3a allele appears to occur at both Aat-3 loci in $S$. vulgaris it is not possible to determine the exact genotype of an individual containing this allele from its isozyme phenotype. The analysis of Aat-3 diversity in $S$. vulgaris is restricted, therefore, to an examination of phenotype frequencies. All populations monomorphic for the non-radiate morph (var. vulgaris) were monomorphic for the Aat-3ab phenotype (Table 4). This phenotype was also predominant (frequency 0.97) among non-radiate plants in populations polymorphic for capitulum type, being fixed in 8 of 13 polymorphic populations surveyed. In contrast, var. hibernicus was monomorphic for the Aat-3ac phenotype in one population (at Methil), and in nine of the remaining 12 populations surveyed, was polymorphic for Aat-3 phenotype. None of the populations surveyed contained individuals which produced a single-banded phenotype, i.e. were homozygous for the same allele at each duplicated locus. Taken over all individuals surveyed, it was apparent that whereas the Aat-3c allele was common in var. hibernicus, it was very rare among individuals of var. vulgaris which cooccurred with var. hibernicus, and was absent from British, Irish and mainland European populations monomorphic for var. vulgaris. In populations polymorphic for capitulum type, both $S$. vulgaris variants exhibited a marked deficiency of observed free heterozygotes, i.e. six-banded phenotypes at the Aat-3 locus (Table 4), indicating a high level of inbreeding.

\section{Discussion}

The results of the survey of allozyme variation for AAT in $S$. squalidus and $S$. vulgaris has provided strong evidence that the radiate variant of $S$. vulgaris var. hibernicus $(2 n=40)$ originated following introgression of genetic material across a chromosome barrier from $S$. squalidus $(2 n=20)$ into the non-radiate $S$. vulgaris $(2 n=40)$. The Aat-3c allele which occured at high frequency in $S$. squalidus (74 per cent of 687 plants surveyed), was also common in $S$. vulgaris var. hibernicus (present in 47 per cent of 351 plants tested), but was rare among individuals of var. vulgaris which co-occurred with var. hibernicus ( 3 per cent of 384 plants examined), and was absent from populations monomorphic for var. vulgaris (428 plants tested). Taken together with the historical, morphological, and crossing evidence previously reported (Stace, 1977; Ingram et al., 1980), this genetic evidence can be taken as confirmation of an introgressive origin of S. vulgaris var. hibernicus.

Introgression of the Aat-3c allele from $S$. squalidus into $S$. vulgaris could have proceeded along two pathways. Either via backcrossing following the formation of a triploid $F_{1}$ hybrid $(2 n=30)$, as postulated and demonstrated previously for the introgression of the ray floret allele into $S$. vulgaris (Ingram, 1978; Ingram et al., 1980), or alternatively via backcrossing following the formation of a tetraploid $F_{1}$ hybrid $(2 n=40)$. Fusion of an unreduced $S$. squalidus gamete with a normal gamete of $S$. vulgaris var. vulgaris would produce a tetraploid $F_{1}$ which is likely to exhibit higher pollen fertility than a triploid $F_{1}$ and thus facilitate introgression more easily. Currently it is not possible to state with certainty along which of these two pathways introgression has proceeded, and it is feasible that both pathways were involved in the transfer of the $A a t-3 c$ allele from $S$. squalidus. The fact that the Aat-3a allele has remained absent from $S$. squalidus in Britain, although common in $S$. vulgaris, is evidence against introgression proceeding from $S$. vulgaris into $S$. squalidus.

The radiate variant of $S$. vulgaris differs markedly from the non-radiate form in mating system. In populations polymorphic for capitulum type, non-radiate var. vulgaris normally outcrosses at a rate of $\leqslant 1$ per cent, whereas radiate var. hibernicus shows between 3 and 35 per cent outcrossing (Marshall \& Abbott, 1982, 1984a). This difference has been attributed, in part, to (i) the pistillate ray florets of radiate plants outcrossing at higher frequencies than the hermaphroditic disc florets of which non-radiate capitula are entirely composed (Marshall \& Abbott, 1984b); and (ii) greater relative attractiveness of radiate capitula to pollinators due to the presence of ray florets (Abbott \& Irwin, 1988). Because of its greater outcrossing rate, var. hibernicus is subject to a 'cost of outcrossing' in populations polymorphic for capitulum type (Fisher, 1941; Maynard-Smith, 1978; Lloyd, 1979); despite this disadvantage, however it has spread widely in Britain since its origin in the 19th century (Stace, 
1977). Elsewhere, Abbott (1986) and Abbott \& Horrill (1991) have suggested that the success of the radiate variant is likely to stem from the beneficial effects of other genes introgressed into $S$. vulgaris along with the radiate allele, and now stabilized in var. hibernicus, rather than any direct benefits of increased outcrossing per se, e.g. a reduction in inbreeding depression (Charlesworth \& Charlesworth, 1987). The occurrence of the Aat-3c allele in var. hibernicus, provides evidence that a specific gene other than the radiate allele has been introgressed into the taxon at one locus and, as a result, the variant shows an increased level of allelic variation at this locus.

A surprising result to emerge from the genetic analysis of Aat-3 variation in S. vulgaris was the presence of the ' $a$ ' allele at both Aat-3 loci within the species. It would follow that some individuals homozygous for the ' $a$ ' allele at each locus and producing therefore a singlebanded phenotype would be expected to have been detected in the survey of Aat-3 variation in wild material. In no instance, however, were such individuals found (Table 4). If the Aat-3ab phenotype is produced only by the Aat-3aa,bb genotype while the Aat-3ac phenotype is produced only by the Aat-3cc,aa genotype [as indicated by the genetic analysis (Table 1)], then segregation of the Aat-3aa,aa genotype would not occur in populations of non-radiate $S$. vulgaris var. vulgaris (all of which are monomorphic for the Aat-3ab phenotype), but should occur in those populations polymorphic for capitulum type which contain the Aat-

Table 4 Aat-3 phenotype frequencies in $S$. vulgaris var. vulgaris (V) and var. hibernicus $(\mathrm{H})$

\begin{tabular}{|c|c|c|c|c|c|c|c|}
\hline \multirow[b]{2}{*}{ Population } & \multirow{2}{*}{$\begin{array}{l}\text { National Grid } \\
\text { Reference }\end{array}$} & \multirow[b]{2}{*}{ Variant } & \multirow{2}{*}{$\begin{array}{l}\text { Sample } \\
\text { size }\end{array}$} & \multicolumn{4}{|c|}{ Phenotype frequency } \\
\hline & & & & $a b$ & $a c$ & $b c$ & $a b c$ \\
\hline \multicolumn{8}{|c|}{ Polymorphic for var. vulgaris and var. hibernicus } \\
\hline \multicolumn{8}{|c|}{ England } \\
\hline \multirow[t]{2}{*}{ Birmingham } & SP045835 & V & 50 & 1.00 & - & - & - \\
\hline & & $\mathrm{H}$ & 50 & 1.00 & - & - & - \\
\hline \multirow[t]{2}{*}{ St Helens } & SJ524944 & V & 40 & 1.00 & - & - & - \\
\hline & & $\mathrm{H}$ & 40 & 0.85 & 0.12 & 0.03 & - \\
\hline \multicolumn{8}{|l|}{ Scotland } \\
\hline \multirow{2}{*}{ Glasgow (i) } & NS578664 & V & 25 & 1.00 & - & - & - \\
\hline & & $\mathrm{H}$ & 25 & 1.00 & - & - & - \\
\hline \multirow[t]{2}{*}{ Glasgow (ii) } & NS534671 & V & 25 & 1.00 & - & - & - \\
\hline & & $\mathrm{H}$ & 25 & 0.44 & 0.48 & 0.08 & - \\
\hline \multirow[t]{2}{*}{ Grangemouth (i) } & NS913823 & $\mathrm{V}$ & 25 & 0.96 & - & 0.04 & - \\
\hline & & $\mathrm{H}$ & 25 & 0.32 & 0.68 & - & - \\
\hline \multirow[t]{2}{*}{ Grangemouth (ii) } & NS977814 & V & 25 & 1.00 & - & - & - \\
\hline & & $\mathrm{H}$ & 25 & 1.00 & - & - & - \\
\hline \multirow{2}{*}{ Edinburgh } & NT268765 & $\mathrm{V}$ & 27 & 0.92 & 0.04 & 0.04 & - \\
\hline & & $\mathrm{H}$ & 25 & 0.28 & 0.08 & 0.64 & - \\
\hline \multirow[t]{2}{*}{ Methil } & NT376995 & V & 32 & 1.00 & - & - & - \\
\hline & & $\mathrm{H}$ & 36 & - & 1.00 & - & - \\
\hline \multicolumn{8}{|l|}{ Wales } \\
\hline \multirow[t]{2}{*}{ Mochdre } & SH822781 & $\mathrm{V}$ & 20 & 1.00 & - & - & - \\
\hline & & $\mathrm{H}$ & 24 & 0.08 & 0.88 & 0.04 & - \\
\hline \multicolumn{8}{|l|}{ Wrexham } \\
\hline \multirow[t]{2}{*}{ Brymbo } & SJ296539 & V & 38 & 0.87 & 0.03 & 0.03 & 0.07 \\
\hline & & $\mathrm{H}$ & 21 & 0.38 & 0.33 & 0.29 & - \\
\hline \multirow[t]{2}{*}{ Ffrith } & SJ286556 & V & 10 & 1.00 & - & - & - \\
\hline & & $\mathrm{H}$ & 16 & - & 0.87 & 0.13 & - \\
\hline \multirow[t]{2}{*}{ Rhostyllen } & SJ312492 & V & 23 & 0.96 & - & 0.04 & - \\
\hline & & $\mathrm{H}$ & 15 & 0.73 & - & 0.27 & - \\
\hline \multirow[t]{2}{*}{ Southsea } & SJ306515 & V & 44 & 0.96 & - & 0.02 & 0.02 \\
\hline & & $\mathrm{H}$ & 24 & 0.25 & 0.17 & 0.50 & 0.08 \\
\hline \multirow[t]{2}{*}{ Total } & & V & 384 & 0.971 & 0.005 & 0.013 & 0.011 \\
\hline & & $\mathrm{H}$ & 351 & 0.533 & 0.336 & 0.125 & 0.006 \\
\hline
\end{tabular}




\begin{tabular}{|c|c|c|c|c|c|c|c|}
\hline \multirow[b]{2}{*}{ Population } & \multirow{2}{*}{$\begin{array}{l}\text { National Grid } \\
\text { Reference }\end{array}$} & \multirow[b]{2}{*}{ Variant } & \multirow{2}{*}{$\begin{array}{l}\text { Sample } \\
\text { size }\end{array}$} & \multicolumn{4}{|c|}{ Phenotype frequency } \\
\hline & & & & $a b$ & $a c$ & $b c$ & $a b c$ \\
\hline \multicolumn{8}{|c|}{ Monomorphic for var. vulgaris } \\
\hline \multicolumn{8}{|l|}{ Britain } \\
\hline \multicolumn{8}{|l|}{ England } \\
\hline London & TQ349807 & $\mathrm{V}$ & 45 & 1.00 & - & - & - \\
\hline Workington & NX994295 & V & 40 & 1.00 & - & - & - \\
\hline \multicolumn{8}{|l|}{ Scotland } \\
\hline Dundee & NO394295 & V & 45 & 1.00 & - & - & - \\
\hline Kirriemuir & NO388533 & $\mathrm{V}$ & 27 & 1.00 & - & - & - \\
\hline St Andrews & NO510165 & V & 100 & 1.00 & - & - & - \\
\hline \multicolumn{8}{|l|}{ Wales } \\
\hline Aberffraw & SH366656 & V & 10 & 1.00 & - & - & - \\
\hline Puffin Island & SH653824 & $\mathrm{V}$ & 10 & 1.00 & - & - & - \\
\hline \multicolumn{8}{|l|}{ Ireland } \\
\hline Glengariff & & V & 26 & 1.00 & - & - & - \\
\hline \multicolumn{8}{|l|}{ Mainland Europe } \\
\hline \multicolumn{8}{|l|}{ France } \\
\hline Pont Croix (Brittany) & & $\mathrm{V}$ & 21 & 1.00 & - & - & - \\
\hline \multicolumn{8}{|l|}{ Poland } \\
\hline Warsaw & & $\mathrm{V}$ & 29 & 1.00 & - & - & - \\
\hline \multicolumn{8}{|l|}{ Spain } \\
\hline Bejar & & V & 19 & 1.00 & - & - & - \\
\hline Matalascanas & & V & 37 & 1.00 & - & - & - \\
\hline \multicolumn{8}{|l|}{ Switzerland } \\
\hline Basel & & $\mathrm{V}$ & 11 & 1.00 & - & - & - \\
\hline Grindelwald & & $\mathrm{V}$ & 4 & 1.00 & - & - & - \\
\hline Interlaken & & V & 4 & 1.00 & - & - & - \\
\hline Total & & V & 428 & 1.00 & - & - & - \\
\hline
\end{tabular}

$3 a b$ and $A a t-3 a c$ phenotypes. The absence of the Aat$3 a a, a a$ genotype from these latter populations remains a puzzle, unless the genotype exhibits low relative fitness or there is a lack of crossing between the Aat-3ab and $3 a c$ phenotypes in the wild.

Assuming that individuals of $S$. vulgaris var. vulgaris in populations which are monomorphic for non-radiate capitulum type are all of $A a t-3 a a, b b$ genotype, then it is of interest to speculate on how the Aat-3a allele became established at the second Aat-3 locus as in the Aat-3cc,aa genotype. Although mutation cannot be ruled out, the most likely explanation is that during the introgressive origin of var. hibernicus, recombination between homoeologous chromosomes occurred and resulted in the transfer of the ' $a$ ' allele between the two Aat-3 loci in $S$. vulgaris. In this respect, it is of interest that multivalent formation, which provides opportunities for recombination to occur between homoeologous chromosomes, has been recorded by Ingram $(1977,1978)$ at meiosis in the artificially synthesized triploid hybrid between $S$. vulgaris and $S$. squalidus and also in the backcross progeny to $S$. vulgaris.
Finally, in view of the close association recorded between the Aat-3c allele and the radiate allele in populations of $S$. vulgaris polymorphic for capitulum type, it is somewhat surprising that neither Aat-3 locus was found to be linked to the ray floret locus. Because the maternal outcrossing rate of the radiate morph resulting from intermorph crosses can reach 35 per cent in some polymorphic populations, it may have been anticipated that the $A a t-3 c$ allele would be more common in non-radiate plants (i.e. those which cooccur with the radiate morph) than was recorded. It is possible that the strong association which is present between the $A a t-3 c$ and ray floret alleles is maintained by selection favouring a co-adapted complex of genes that has been introgressed from $S$. squalidus. Alternatively, or in addition, there may be positive assortative mating between genotypes at the Aat-3 locus which would greatly reduce the rate of transfer of the Aat-3c allele from var. hibernicus to var. vulgaris. The rarity with which six-banded heterozygotes at the Aat-3 locus were recorded in wild polymorphic populations (Table 4) lends some support to this second possibility. 
In conclusion, it is worth considering whether var. hibernicus may have originated via introgression more than once in Britain. In the wild, the triploid $F_{1}$ hybrid is produced at very low frequencies in areas where $S$. squalidus and $S$. vulgaris co-occur (Marshall \& Abbott, 1980); nevertheless such hybrids, verified by cytological analysis, have been reported from several locations throughout Britain (Stace, 1977; Brettell \& Leslie, 1978; Marshall \& Abbott, 1980; Taylor, 1984). Records of the putative tetraploid $F_{1}$ hybrid in Britain are less frequent and have been reported only twice (Crisp, 1972; Taylor, 1984). Early backcross products are likely to resemble $S$. vulgaris var. hibernicus quite closely (at least when the triploid hybrid is involved), but with reduced fertility and perhaps a more intermediate and less stable phenotype (Ingram et al., 1980). Consequently, they are likely to be overlooked in natural populations. The only detailed survey, to date, of the possible occurrence of early backcross individuals in the wild, is that of Crisp (1972) on herbarium material collected in the British Isles from the mid19th century to 1930 . Crisp (1972) identified what appeared to be early backcrossed products at four locations: i.e. around Oxford, at Cork (Ireland), the Bristol/Cardiff area and the north-east Wales/Cheshire area. Within each of these areas, var. hibernicus was present before 1900 , and it is feasible that in each case a separate origin of the taxon had occurred. Based on Crisp's findings, therefore, it would seem that var. hibernicus may have originated independently via introgression at several different locations in Britain during the past 150 years or so, following local hybridization between $S$. vulgaris var. vulgaris and $S$. squalidus. More precise evidence is required on this point, however, before such a conclusion is readily accepted.

\section{Acknowledgements}

Part of this research was conducted while PAA was in receipt of a postgraduate research studentship funded by the NERC. We are grateful to Christine Wilson for providing seed of $S$. vulgaris from Warsaw. We also wish to thank an anonymous reviewer whose constructive comments greatly improved the original manuscript.

\section{References}

ABBOTT, R. J. 1986. Life history variation associated with the polymorphism for capitulum type and outcrossing rate in $S$. vulgaris. Heredity, 56, 381-392.

ABBOTT, R. J. AND HORRILL, J. C. 1991. Survivorship and fecundity of the radiate and non-radiate morphs of groundsel,
Senecio vulgaris L., raised in pure stand and mixture. $J$. Evol. Biol., 4, 241-257.

ABBOTT, R. J. AND IRWIN, J. A. 1988. Pollinator movements and the polymorphism for outcrossing rate in Groundsel, Senecio vulgaris L. Heredity, 60, 295-298.

ALEXANDER, J. C. M. 1979. The Mediterranean species of Senecio sections Senecio and Delphinifolius. Notes. Roy. Bot. Gard. Edin., 27, 387-428.

ALLARD, R. W. 1956. Formulas and tables to facilitate the calculation of recombination values in heredity. Hilgardia, 24, 235-278.

ANDERSON, E. 1949. Introgressive Hybridization. John Wiley, New York.

ARNOLD, M. L., HAMRICK, J. L. AND BENNETT, B. D. 1990. Allozyme variation in Louisiana irises: a test for introgression and hybrid speciation. Heredity, 65, 297-306.

ASHTON, P. A. 1990. Multiple Origins of Senecio cambrensis Rosser, and Related Evolutionary Studies in British Senecio. Unpublished Ph.D. Thesis, University of St Andrews.

BLOOM, w. L. 1976. Multivariate analysis of the introgressive replacement of Clarkia nitens by Clarkia speciosa polyantha. Evolution, 30, 412-424.

BRETTELL, R. I. S. AND LESLIE, A. C. 1978. Senecio squalidus L. $\times S$. vulgaris L. in Cambridgeshire. Watsonia, 12, 155.

BRIGGS, D. AND WALTERS, S. M. 1984. Plant Variation and Evolution. 2nd edn, Cambridge University Press, Cambridge.

CHARLESWORTH, D. AND CHARLESWORTH, B. 1987. Inbreeding depression and its evolutionary consequences. Ann. Rev. Ecol. Syst., 18, 237-268.

CRISP, P. C. 1972. Cytotaxonomic studies in the section Annui of Senecio. Unpublished Ph.D. Thesis, University of London.

DAVIS, J. L. 1985. Introgression in Central American Phytolacca (Phytolaccaceae). Am. J. Bot., 72, 1944-1953.

DRUCE, G. C. 1927. The Flora of Oxfordshire. 2nd edn, Clarendon Press, Oxford.

ELLSTRAND, N. C., LEE, J. H., KEELEY, J. E. AND KEELEY, S. C. 1987. Ecological isolation and introgression: biochemical confirmation of introgression in an Arctostaphylos (Ericaceae) population. Acta. Oecol., 8,299-308.

FISHER, R. A. 1941. Average excess and average effect of a gene substitution. Ann. Eugen., 11, 53-63.

GIBBS, P. E., MILNE, C. AND VARGAS CARRILLO, M. 1975. Correlation between the breeding system and recombination index in five species of Senecio. New Phytol., 75, 619-626.

GOTTLIEB, L. D. 1973. Genetic control of glutamate oxaloacetate transaminase isozymes in the diploid plant Stephanomeria exigua and its allopolyploid derivatives. $\mathrm{Bi}$ ochem. Genet., 9, 97-107.

GRANT, v. 1950. Genetic and taxonomic studies in Gilia. Aliso, 2, 239-316.

Grant, v. 1981. Plant Speciation. 2nd edn, Columbia University Press, New York.

HAMRICK, J. L. AND GODT, M. J. w. 1990. Allozyme diversity in plant species, pp. 43-63. In: Brown, A. H. D., Clegg, M. T., Kahler, A. L. and Weir, B. S. (eds) Plant Population Genetics, Breeding, and Genetic Resources. Sinauer, MA, pp. 43-63. 
HARPER, J. L. AND wOoD, w. A. 1957. Biological Flora of the British Isles. Senecio jacobaea L. J. Ecol., 45, 617-637.

HARTL, D. L. 1981. A Primer of Population Genetics. Sinauer, MA.

HEISER, C. B. 1949. Study in the evolution of the sunflower species Helianthus annuus and H. bolanderi. Univ. Calif. Publ. Bot., 23, 157-196.

HEISER, С. в. 1951. Hybridization in the annual sunflowers Helianthus annuus $\times H$. debilis var. cucumerifolius. Evolution, 5, 42-51.

HEISER, C. в. 1973. Introgression re-examined. Bot. Rev., 39, 347-366.

HULL, P. 1974. Self-fertilisation and the distribution of the radiate form of Senecio vulgaris $\mathrm{L}$. in Central Scotland. Watsonia, 10, 69-75.

INGRAM, R. 1977. Synthesis of the hybrid Senecio squalidus L. $\times$ S. vulgaris L. F. radiatus Hegi. Heredity, 39, 171-173.

INGRAM, R. 1978. The genomic relationship of Senecio squalidus $\mathbf{L}$. and $S$. vulgaris $\mathbf{L}$. and the significance of genomic balance in their hybrid, $\mathrm{S} . \times$ baxteri Druce. $\mathrm{Her}$ edity, 40, 459-462.

INGRAM, R. AND TAYLOR, L. 1982. The genetic control of a nonradiate condition in Senecio squalidus $\mathrm{L}$. and some observations on the role of ray florets in the Compositae. New Phytol., 91, 749-756.

INGRAM, R., WEIR, J. A. AND ABBOTT, R. J. 1980. New evidence concerning the origin of inland radiate groundsel Senecio vulgaris L. var. hibernicus Syme., New Phytol., 84, 543-546.

LEVIN, D. A. 1963. Natural hybridization between Phlox maculata and $P$. glaberrima and its evolutionary significance. Am. J. Bot., 50, 714-719.

LEVIN, D. A. 1975. Interspecific hybridization, heterozygosity and gene exchange in Phlox. Evolution, 29, 37-51.

LLOYD, D. G. 1979. Some reproductive factors affecting the selection of self-fertilization in plants. Am. Nat., 113, 67-79.

MARSHALL, D. F. AND ABBOTT, R. J. 1980. On the frequency of introgression of the radiate $\left(T_{r}\right)$ allele from Senecio squalidus L. into Senecio vulgaris L. Heredity, 45, 133-135.

MARShALL, D. F. AND ABBOTT, R. J. 1982. Polymorphism for outcrossing frequency at the ray floret locus in Senecio vulgaris L. I. Evidence. Heredity, 48, 227-235.

MARSHALL, D. F. AND ABBOTT, R. J. 1984a. Polymorphism for outcrossing frequency at the ray floret locus in Senecio vulgaris L. II. Confirmation. Heredity, 52, 331-336.

MARShall, D. F. AND ABBotT, R. J. 1984b. Polymorphism for outcrossing frequency at the ray floret locus in Senecio vulgaris L. III. Causes. Heredity, 53, 145-149.

MAYNARD SMITH, J. 1978. The ecology of sex. In: J. R. Krebs and N. B. Davies (eds) Behavioural Ecology: An Evolutionary Approach. Blackwell Scientific Publications Ltd, Oxford, pp. 159-179.
MONAGHAN, J. AND HULL, P. 1976. Differences in vegetative characteristics among four populations of Senecio vulgaris L. possibly due to interspecific hybridization. Ann. Bot., 40, 125-128.

NEI, M. 1973. Analysis of gene diversity in subdivided populations. Proc. Nat. Acad. Sci. U.S.A., 70, 3321-3323.

OLIVIERI, I. 1985. Comparative electrophoretic studies of Carduus pynochephalus L., C. tenuiflorus Curt. (Asteraceae) and their hybrids. Am. J. Bot., 72, 715-718.

ORNDUFF, R. 1964. Evoltionary pathways of the Senecio lautus alliance in New Zealand and Australia. Evolution, 18, 349-360.

ORNDUFF, R. 1967. Hybridization and regional variation in Pacific Northwestern Impatiens (Balsaminaceae). Brittonia, 19, 122-128.

RIESEBERG, L. H., BECKSTROM-STERNBERG, S. AND DOAN, K. 1990. Helianthus annuus ssp. texanus has chloroplast DNA and nuclear ribosomal RNA genes of Helianthus debilis ssp. cucumerifolius. Proc. Natl. Acad. Sci. U.S.A., 87, 593-597.

RIESEBERG, L. H., SOLTIS, D. E. AND PALMER, J. D. 1988. A molecular re-examination of introgression between Helainthus annuus and $H$. bolanderi (Compositae). Evolution, 42, 227-238

ROLLO, C. D., MACFARLANE, J. D. AND SMITH, B. S. 1985. Electrophoretic and allometric variation in burdock (Arctium spp): hybridization and its ecological implications. Can.J. Bot., 63, 1255-1261.

STACE, C. A. 1977. The origin of radiate Senecio vulgaris $\mathrm{L}$. Heredity, 39, 383-388.

STACE, C. A. 1987. Hybridization and the Plant Species. In: Urbanska, K. M. (ed.) Differentiation Patterns in Higher Plants. Academic Press, London, pp. 115-127.

STEBbins, G. L. 1959. The role of hybridization in evolution. Proc. Am. Phil. Soc., 103, 231-251.

STEBbins, G. L. 1969. The significance of hybridization for plant taxonomy and evolution. Taxon, 18, 26-35.

SOLTIS, D. E. AND SOLTIS, P. S. 1986. Intergeneric hybridization between Conimitella williamsii and Mitella stauropetala (Saxifragaceae). Syst. Bot., 11, 293-297.

SUITER, K. A., WENDEL, J. F. AND CASE, J. S. 1983. LINKAGE-1: a PASCAL computer program for the detection and analysis of genetic linkage. J. Hered., 74, 203-204.

SYME, J. T. B. 1875 . Senecio vulgaris L. var. hibernica mihi. Botl. Exch. Club, Rep. Curators, 1872-74, 27-28.

TAYLOR, L. 1984. The potential for introgression in a British polyploid complex. Unpublished Ph.D. Thesis, University of St. Andrews.

TROW, A. H. 1912. On the inheritance of certain characters in the Common Groundsel, Senecio vulgaris L., and its segregates. J. Genet., 2, 239-276.

WEEDEN, N. F. AND WENDEL, J. F. 1989. Genetics of plant isozymes. In: Soltis, D. E. and Soltis, P. S. (eds) Isozymes in Plant Biology. Chapman and Hall, London, pp. 46-72.

WRIGHT, s. 1951. The genetical structure of populations. Ann. Eugen., 15, 323-354. 